\title{
AB'ye Üye Ülkelerde Sanayileşmenin Belirleyicileri: Dinamik Panel Veri Analizi
}

\author{
Özge ERDÖLEK KOZAL*, Gülçin GÜREL GÜNAL**
}

ÖZ

Sanayileşme, ilk sanayi devriminden bugüne, başta Avrupa olmak üzere tüm dünyada ekonomik, politik ve sosyal dönüşümlere sebep olmuştur. 21. yüzyılda da Avrupa öncülüğünde ilan edilen yeni sanayileşme dalgasıyla da sürdürülebilir büyüme ve kalkınmanın itici gücü olarak yeniden tartışmaya açılmıştır. Bu çerçevede, son 10 yılda Avrupa Birliği'ne (AB) üye ülkelerde de yeni bölgesel politika arayışları gündeme gelmiş ve özellikle AB'nde yeniden sanayileşme için bir yol haritası ihtiyacı ortaya çıkmıştır. Bu nedenle bu çalışmada, AB'ye üye ülkelerde sanayileşmeyi etkileyen unsurlar, 1995-2018 yılları için iki aşamalı sistem GMM yöntemi kullanılarak analiz edilmektedir. Çalışmanın bulguları, AB üye ülkelerinde sermaye ve beşerî sermaye stoku, dışa açıklık, göreli gelir, enflasyon, bankalar tarafından özel sektöre sağlanan krediler, 2008 krizi gibi temel ekonomik göstergeler ile kurumsal altyapı gibi sosyoekonomik genel görünümle ilişkili olan göstergeleri sanayileşmeyi etkileyen ana unsurlar olarak ortaya koymaktadır.

Anahtar Kelimeler: Sanayileşme, İmalat Sanayi, Avrupa Birliği, Panel Veri Analizi, Sistem GMM

JEL Sinıflandırması: C33, L6, O52

\section{Determinants of Industrialization in Member States of the European Union: Dynamic Panel Data Analysis}

\begin{abstract}
Since the first industrial revolution, industrialization has caused important economic, politic, and social transformations in the world, especially in Europe. With the new industrial wave leaded by Europe in the 21st century, industrialization has begun to be reconsidered as one of the main drivers of sustainable economic growth and development. In this context, in the last decade, the search for new regional policies has also been on the agenda of the EU member countries and the need for a roadmap for the reindustrialization process of the EU has emerged. Therefore, in this study, the main determinants of industrialization in EU member countries for the 1995-2018 are examined using the two-stage system GMM approach. Findings reveal that, main economic indicators such as, capital, and human capital stock, economic openness, relative income, inflation, domestic credits provided by banks to private sector, 2008 crisis and indicator that is related to socio-economic structure of the countries such as institutional background are the main factors affecting industrialization in EU.
\end{abstract}

Keywords: Industrialization, Manufacturing, European Union, Panel Data Analysis, System GMM

JEL Classification: C33, L6, O52

Geliş Tarihi / Received: 06.06.2021 Kabul Tarihi / Accepted: 20.09.2021 Doi: 10.17541/optimum.946057

\footnotetext{
* Arş. Gör. Dr., Ege Üniversitesi, İIBF, İktisat Bölümü, ozge.kozal@ege.edu.tr, ORCID: 0000-0002-5542-6290

** Arş. Gör. Dr., Ege Üniversitesi, İ̈BF, İktisat Bölümü, gulcngurel@ gmail.com, ORCID: 0000-0003-4780-4420
} 


\section{GİRIŞ}

Sanayileşme, imalat sanayi faaliyetlerinin artan önemini ve dönüşümünü kapsayan bir sosyoekonomik süreç olarak tanımlanmaktadır (O’Brien, 2001). Sanayileşmenin temel dinamikleri, Sanayi Devrimi’nden bugüne, ülkelerin iktisadi büyüme ve kalkınma süreçlerine etkileri bağlamında önemini koruyan bir tartışma alanı olmuştur. Çünkü sanayileşmenin büyüme ve kalkınma için bir önkoşul olduğu hususunda neredeyse bir görüş birliği vardır (Szirmai ve Verspagen, 2015). Özellikle İkinci Dünya Savaşı'nın ardından yeniden yapılanan dünya ekonomisinde, sanayileşmenin "ekonomik büyümenin motoru" olup olmadığı sorusuna yanıt arayan teorik ve ampirik tartışmalar hız kazanmış, Kaldor (1966) ve Cornwall (1977) tarafından sistematik bir biçimde tartışmaya açılan imalat sanayinin büyümenin motoru olduğu hipotezi, 20. yüzyılın ikinci yarısında önemli bir gündem maddesi haline gelmiştir (Thirlwall, 2003).

18. yüzyıldan 20. yüzyılın ikinci yarısına kadar öncelikle büyüme, ardından da kalkınma/modernleşme ile özdeş süreçler olarak kabul edilen sanayileşme, 20. yüzyılın ikinci yarısından itibaren neredeyse tüm dünyada finansal sermayeye dayalı büyüme politikalarının yükselmesi ile büyük ölçüde gözden düşmüştür. Nitekim, küreselleşmenin arttığı, bilgi ve iletişim teknolojilerinde hızlı gelişmelerin yaşandığı, ülkelerarası sermaye ve emek hareketlerinin giderek daha serbest hale geldiği 1990'lı yıllarda, hizmetler sektörünün dünya Gayrisafi Yurtiçi Hasıla (GSYIH) içindeki payı \%60'a ulaşırken, imalat sanayinin payı ise \%19 düzeyinde kalmıştır (World Bank, 2019). Ancak, son yıllarda, ilk olarak 2008 krizinin neredeyse tüm ülke ekonomilerine yansıması ve bunun iktisat paradigmasında yeni arayışları beraberinde getirmesi, ardından da teknoloji alanındaki yeni gelişmelerin sanayi üretiminin organizasyonunda öngördüğü büyük değişmelerle birlikte yeniden sanayileşme tartışmaları hız kazanmıştır. 2010 yılını takiben Almanya öncülüğünde ilan edilen, üretimde otomasyon ve üretimin aşamalarındaki aktörlerin eşanlı koordinasyonunu temel alan, robotik üretim ile özdeş kabul edilen yeni sanayi atılımı da özellikle 2008 krizi sonrasında üretimin yeniden örgütlemesi konusunda yeniden sanayileşme tartışmalarında önemli bir kırılmaya işaret etmiştir. Önümüzdeki yaklaşık 30 yılda, başta Avrupa olmak üzere, ülkelerin sanayileşme yarışında yeni bir döneme, yeni öncü sektörler ile girmeleri beklenmektedir (Kozal ve Barbaros, 2019).

Sanayileşmenin bölgesel özgüllükler çerçevesinde farklı görüntüler kazandığ1 söylenebilir. Bu yeni sanayi dalgası ve sanayileşmenin tarihsel süreçte nasıl evrimleştiği incelendiğinde de ilk Sanayi Devrimi'nden bugüne sanayileşmenin başta İngiltere ve Almanya olmak üzere Avrupa ülkelerinde ekonomik ve sosyal yapıda önemli dönüşümler yarattı̆̆ (Landes, 1969) ve bu dönüşümlerin dünyadaki sanayileşme yarışına da yön verdiği görülmektedir. Yani Avrupa ülkeleri hem kurdukları uluslararası örgütün ekonomik ve politik gücü hem de tarihsel olarak sanayileşme yarışına yön vermeleri sebebiyle dünya ekonomisine önemli ölçüde etki etmektedir. Bununla birlikte $A B$, siyasi ve ekonomik iş birliklerinin giderek önem kazandığı günümüzde hem yeni sanayileşme dalgasının öncü ülkelerini bünyesinde bulundurması hem de son 20 yıldaki çeşitli ekonomik ve sosyal kırılmalar (genişleme politikaları, 2008 krizi, göç sorunu vb.) nedeniyle oldukça dikkat çekici bir konumdadır. Bu nedenle, Avrupa Birliği'nde sanayileşmenin dinamiklerinin yakından incelenmesi, yeniden sanayileşme tartışmalarının ampirik zeminine katkı sağlayacağı için son derece önemlidir.

1995 yılında birliğe üye olan ülkelerle dördüncü genişlemesini yaşayan $\mathrm{AB}$, bu yılda dünya sanayi katma değerinin yaklaşı \%27'sini oluşturmaktadır. 2018 yılında ise, üye ülkelerin sanayi katma değerine katkısı \%14'e gerilese de bünyesindeki ülke sayısının 2018 yılında 28 olduğu düşünüldüğünde, az sayıdaki ülkenin dünya üretimine katkı düzeyinin hala önemini koruduğu söylenebilmektedir. Grafik 1'de de görüldüğü gibi, son 10 yılda AB'ye üye ülkelerin imalat sanayi katma değerinin GSYİH içindeki payı neredeyse aynı kalmakta, ancak AB'ye üye ülkelerde imalat sanayi katma değerinin büyüme oranı 2008'de yaşanan keskin küçülmenin ardından, artış trendine geçmektedir. 
Grafik 1. AB’ye Üye Ülkelerde İmalat Sanayinin Genel Görünümü (1995-2018)

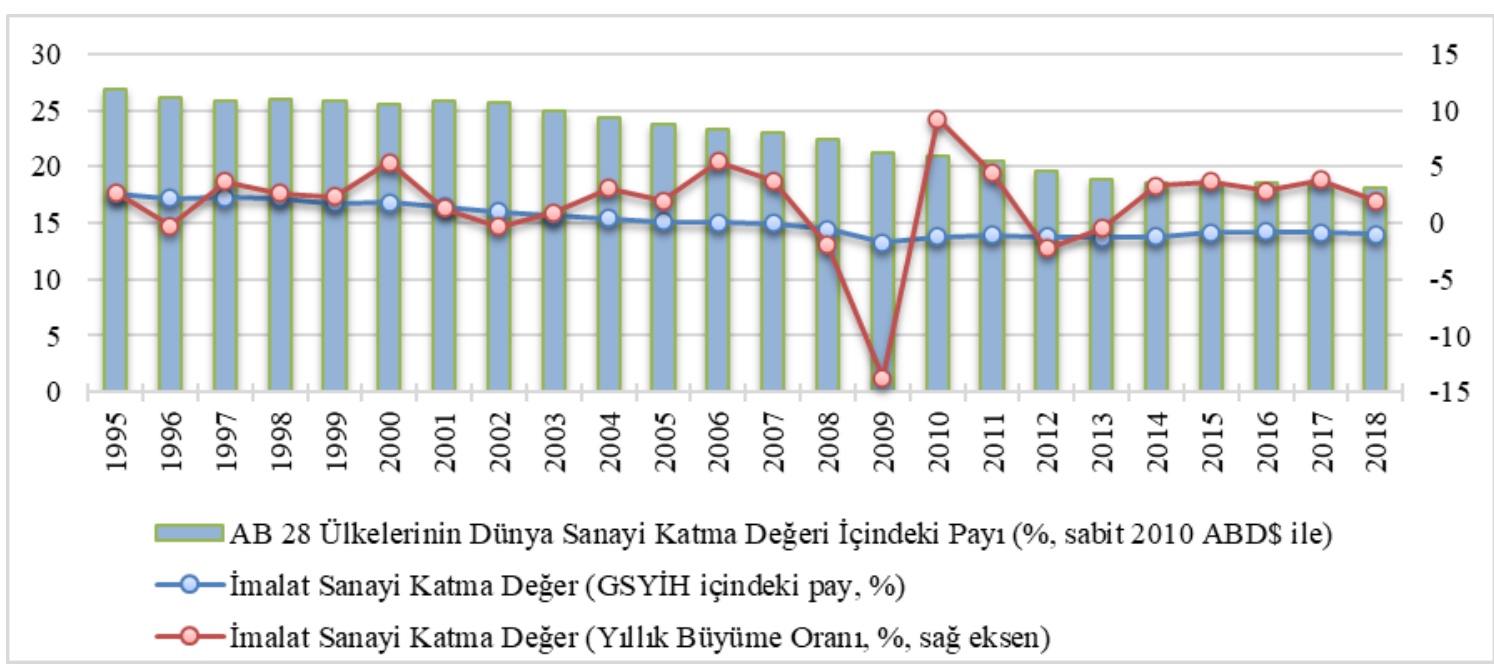

Kaynak: (World Bank, Dünya Kalkınma Göstergeleri, 2019).

Yüksek teknoloji içerikli sanayi ürünleri ile farklı bir görüntü kazanacak olan yeni sanayi atılımında, $A B$ 'ye üye ülkelerin sahip oldukları rolün oldukça önemli olacağı açıktır. Nitekim, AB'ye üye ülkelerde, yüksek ve orta yüksek teknoloji içerikli endüstrilerin imalat sanayi üretim artışının sürükleyicisi olduğuna ve bu ülkelerin değişen dünyanın koşullarına nasıl eklemleneceğinin tüm dünya ekonomisi için önemli olduğuna çok sayıda çalışmada dikkat çekilmektedir (Eurostat, 2013; Gilchrist, 2016; Castelo-Branco vd., 2019; Eurofound, 2019).

Yeniden sanayileşme tartışmalarında ana odak noktası, yakın gelecekte sanayileşmenin tekrar büyüme ve kalkınmanın itici gücü olarak kabul edileceği ve bu nedenle ülkelerin bu döneme uygun yeni sanayi politikası arayışlarına gireceğidir. Bu doğrultuda sanayileşmenin tarihsel dinamikleri ve sanayinin mevcut yapısı, ülkelerin yeni sanayileşme dalgasına nasıl eklemleneceklerini de doğrudan belirleyecektir. Bu çerçevede, AB’ye üye ülkelerde de yeni bölgesel politika arayışları gündeme gelecek ve dünyanın en önemli imalat sanayi üretim bölgelerinden biri olarak kabul edilebilecek olan $A B$ 'ye üye ülkelerde imalat sanayi üretimini yeniden yapılandıracak bir sanayi stratejisine ihtiyaç duyulacaktır. $\mathrm{Bu}$ yol haritasına katkıda bulunulabilmesi için, öncelikle bu ülkelerde sanayileşmeyi etkileyen dinamiklerin tespit edilmesi gerekmektedir. $\mathrm{Bu}$ nedenle bu çalışma, 1995-2018 yılları arasında AB-25 ülkelerinde sanayileşmeyi belirleyen faktörleri tespit etmeyi amaçlamaktadır. İmalat sanayi üretimini etkileyen temel değişkenlerin ortaya konulmasının, iktisadi büyüme ve kalkınmaya yönelik politika üretme kapasitesine önemli katkı sağlayacağı öngörülmektedir.

\section{SANAYİLEŞMENIN BELIRLEYİCILERI}

Sanayileşmenin belirleyicilerine ilişkin tartışmalar iki eksende analiz edilebilmektedir. İlk eksen, sanayileşmenin büyümenin motoru olup olmadığını tartışmaya açan çalışmalardan oluşmaktadır. İlk kez Kaldor (1967) ve Cornwall (1977) tarafindan ampirik olarak ele alınan bu tartışma ekseninde, genel olarak ülkenin imalat sanayi üretiminin, gelir, yatırım ve imalat sanayi verimliliği ile ilişkisi ele alınmaktadır. Bu iki önemli çalışma, ülkelerin kaynaklarını düşük verimli sektörlerden (tarım) daha yüksek verimli sektörlere (imalat sanayi) aktarmaları sonucunda hem bir büyüme ivmesi yakalandığını hem de bu büyümenin kişi başına gelir artışı ile de desteklendiğini göstermektedir. Bu durum literatürde, "yapısal prim (structural bonus)" olarak tanımlanmaktadır (Timmer ve Szirmai, 2000). İmalat sanayi üretiminin büyümenin motoru olup olmadığı sorusu hala güncelliğini koruyan bir tartışma alanıdır. Chenery (1980), McClausland ve Theodossiou (2012), Szirmai ve Verspagen (2015), Marconi vd. (2016) 
gelişmiş ve gelişmekte olan ülkelerde; Mazhar ve Rehman (2019) gelişmekte olan ülkelerde, imalat sanayinin büyümenin motoru olduğu hipotezini farklı analiz yılları için doğrulamaktadır. Ancak, bazı çalışmalar bu hipotezin yalnızca yeni sanayileşen ya da gelişmekte olan ülkelerde geçerli olduğunu, gelişmiş ya da sanayileşmiş ülkelerde geçerli olmadığını ortaya koymaktadır. Örneğin, Fagerberg ve Verspangen (1999), Cornwall'ın genişletilmiş modelini baz aldıkları çalışmada ve Szirmai (2012) bu hipotezin yalnızca yeni sanayileşen ülkeler için geçerli olduğunu, erken sanayileşmiş ve gelişmiş ülkeler için geçerli olmadığını göstermektedir. Dolayısı ile, ülkeler ve analiz dönemleri değiştikçe "imalat sanayi büyümenin motoru mudur?" sorusuna verilen yanıtın değiştiği görülmektedir.

İkinci eksen ise, büyümenin motoru hipotezini test ederken aynı zamanda sanayileşmenin tarihsel belirleyicilerini de ortaya koymayı amaçlayan çalışmalardan oluşmaktadır. Bu alandaki ilk çalışmalardan biri olan Temple ve Voth (1998), gelişmekte olan ülkeler için yaptıkları analizde, sanayileşmenin sürükleyici gücünün beşerî sermaye olduğunu ortaya koymaktadır. Bu bulguya paralel olarak, Szirmai ve Verspangen (2015), yüksek eğitimli işgücü ile imalat sanayi üretim artışı arasında pozitif bir ilişkiyi sunmaktadır. Sanayileşmenin belirleyicileri tartışmasına, gelir, yatırımlar, beşerî sermaye gibi temel değişkenlerin dışında kurumsal altyapıyı dahil eden literatür ise oldukça yenidir ve bu çalışmaların genellikle 2000 yılı ve sonrasında yayınlandığı dikkat çekmektedir. Sanayileşmede kurumların önemine hem teorik hem de ampirik düzeyde dikkat çeken en önemli çalışmaların başında Rodrik'in çalışmaları (2007- 2016) gelmektedir. Rodrik (2016), sanayileşmenin temel dinamiklerinin, sadece gelir ve demografik trendlerle değil, kurumlar, demokratikleşme düzeyi ve küreselleşme ile de yakından ilintili olduğunu ortaya koymaktadır. Ancak Guadagno (2016), teknolojik geriliği ve eksik değerlenmiş döviz kurunu sanayileşmenin belirleyicileri olarak tespit ederken, 1995 sonrasında bilgi birikimi ve yatırımların önemli hale geldiğini ortaya koymakta, Rodrik'in (2016) aksine, kurumsal altyapı ile imalat sanayi üretimi arasındaki ilişkiyi doğrulayamamaktadır.

İmalat sanayinin büyümenin motoru olup olmadığı ve sanayileşmenin belirleyicileri tartışmalarında en çok dikkat çeken, analizlerin gelişmiş ve gelişmekte olan ülkeler ayrımına odaklandığıdır. Özellikle uluslararası rekabete yön veren spesifik ülke gruplarına, iktisadi ya da siyasi ülke bloklarına odaklanan çalışma sayısı oldukça azdır. Nickel vd.'nin (2008) çalışması, 14 OECD ülkesi için sanayisizleşme sürecinin varlığına dikkat çekerek, bir uluslararası örgütün sanayileşme dinamiklerini ele alan ilk çalışmalardandır. Bu çalışmada, özellikle İngiltere, ABD, Almanya ve Japonya gibi ülkelerin imalat sanayi üretimlerinin milli hasıla içindeki paylarının daha hızlı bir biçimde azaldığ sanayi ürünü olmayan malların göreli fiyatlarından kaynaklandığı ortaya konulmaktadır. Kutu ve Ngalawa (2016), BRICS ülkelerinde sanayileşmenin dinamiklerini incelemiş; emek, sermaye, kişi başına düşen gelir, ihracat değişkenlerinin sanayileşmeyi olumlu etkilediği, bununla birlikte ithalat ve döviz kuru değişkenlerinin uzun dönemde sanayileşmeye etkisinin negatif olduğunu ortaya koymuştur. Naude vd. (2013) ise, Kutu ve Ngalawa (2016)'nın bulgularının aksine, Brezilya, Rusya ve Güney Afrika'da bir sanayisizleşme sürecinin varlığını vurgulamıştır. Bu alanda yapılan az sayıdaki ampirik çalışmanın, OECD ve BRICS ülkelerine odaklandığı görülmektedir.

Daha önce de vurgulandığı gibi, sanayileşmenin dinamikleri konusundaki çalışmalar, genellikle gelişmiş ve gelişmekte olan ülkeler ayrımına odaklanarak, temel makro ve mikro ekonomik değişkenleri dikkate almaktadır. Gelişmiş ve gelişmekte olan ülkelere göre yapılan analizler çok önemli olmakla birlikte, iktisadi ve sosyal görünümün giderek farklılaştı̆̆ dünyada, sanayileşme politikalarının üretilmesine kaynaklık etme amacı güden ampirik çalışmaların iktisadi, siyasi ya da coğrafi bölgesel kümelere, uluslararası örgütlere odaklanması da giderek daha önemli hale gelmektedir. Bu yüzyılda, siyasi ve ekonomik iş birlikleri giderek önem kazanmakta, bu gruplarda alınan kararların üye ülkeleri bağlayıcı özellikleri, üye ülkeleri daha entegre hale getirmektedir. $\mathrm{Bu}$ nedenle, $\mathrm{AB}$ üye ülkelerinin de yeniden sanayileşme dalgasındaki önemli pozisyonları, son 20 yılda yaşadıkları iktisadi, politik ve sosyal 
dönüşümlerle birlikte düşünüldüğünde bu ülkelerde sanayileşme dinamiklerinin anlaşılması son derece önemlidir (Barta vd, 2008; Heyman ve Vetter, 2013; Westkämper ve Walter, 2014; Ambroziak, 2015). Ancak, AB'ye üye ülkeler için sanayileşmenin tarihsel dinamiklerini çok boyutlu bir bakış açısı ile tartışmaya açmış, bilinen bir çalışma bulunmamaktadır. AB'ye üye ülkelerde sanayileşmenin tarihsel belirleyicilerinin incelenmesiyle, AB'nin sanayileşme yol haritasına önemli katkıların sunulması beklenmektedir.

\section{AB'ye Üye Ülkelerde Sanayileşmenin Belirleyicilerinin Ampirik Analizi}

$\mathrm{Bu}$ çalışma, ekonometrik yöntemler kullanarak 1995-2018 yılları için AB-25 ülkelerinde sanayileşmeyi belirleyen faktörleri tespit etmeyi amaçlamaktadır.

\subsection{Veri Seti}

1992 yılında imzalanmış olan ve sanayide rekabet edebilirlik maddesinin kabul edilmiş olduğu Maastricht Anlaşması ile ekonomide tek pazar anlayışına geçilmiştir (Avrupa Topluluğu Komisyonu, 1992). 1995 yılında ise topluluk, Avrupa Birliği olarak anılmaya başlamış ve aynı yıl Finlandiya, Avusturya ve İsveç'in de üye ülke statüsü kazanması ile AB'nin dördüncü genişlemesi yaşanmıştır. Bu nedenlerden dolayı çalışmada, ekonomik ve sosyal birçok alanda ortak politikalar izleyen AB'ye üye ülkelerde sanayileşmenin temel belirleyicileri, 1995-2018 yılları için analiz edilmiştir. Bu çerçevede AB'ye üye olan 25 ülke (AB-25) incelenmiş olup, Avusturya, Belçika, Bulgaristan, Çek Cumhuriyeti, Danimarka, Estonya, Finlandiya, Fransa, Almanya, Yunanistan, Macaristan, İrlanda, İtalya, Letonya, Litvanya, Hollanda, Polonya, Portekiz, Romanya, Slovakya, Slovenya, İspanya, İsveç, Hırvatistan ve analiz yılları içerisinde birliğe üye olması nedeniyle İngiltere analizde yer alan ülkelerdir. Veri setinde bulunan boşluklar nedeniyle Malta, Kıbrıs ve Lüksemburg örnekleme dahil edilmemiştir.

Çalışmanın ana amacı sanayileşmenin tarihsel belirleyicilerini AB'ye üye ülkeler için tespit etmektir. $\mathrm{Bu}$ kapsamda modelin kurgusu, imalat sanayinin büyümenin motoru olup olmadığını test eden çalışmalardan hareketle oluşturulmuştur. İncelenen çalışmalarda model tasarımlarının, iktisadi büyümenin dinamikleri ile imalat sanayi üretiminin dinamikleri arasındaki ilişsiden yola çıkılarak oluşturulduğu tespit edilmiştir. Tablo 1'de görüldüğü gibi bu çalışmada da bu ilişki temel alınmış ve sanayileşmeyi etkilemesi beklenen ekonomik ve sosyal çeşitli göstergelerden faydalanılmıştır. Analiz kapsamında, sanayileşmenin belirleyicilerinin tespit edilmesini amaçlayan model kurgulanırken bağımsız değişkenler için vekil (proxy) olabilecek değişkenlerin de kullanılmasıyla çeşitli duyarlılık analizlerinin yapılması da sağlanmıştır ${ }^{1}$. Vekil değişkenlerin kullanıldığı alternatif modellere ilişkin yalnızca önemli noktalar analiz sonuçları bölümünde tartışmaya açılmıştır.

Nihai modelde sanayileşme düzeyinin temel göstergesi olarak imalat sanayi katma değerinin GSYİH içindeki payı bağımlı değişken olarak kullanılmıştır. Cornwall (1977), imalat sanayi üretiminin, gelir, yatırım ve imalat sanayi verimliliğinden etkilendiğini ortaya koyduğu çalışmasında, yatırıma ilişkin değişkenlerin, imalat sanayi üretim değeri/katma değeri içinde örtük olarak içerildiğini ortaya koymuştur. $\mathrm{Bu}$ nedenle çalışma kapsamında yatırıma ilişkin değişkenler göz ardı edilmiş, Solow tipi büyüme denklemlerinden hareketle, Karadağ vd.

\footnotetext{
1 Modelde değişken seçiminde, stepwise regresyon (adım adım regresyon) türü hiyerarşik model seçim yolu izlenmiştir. Bu doğrultuda, düzeltilmiş $\mathrm{R}^{2}$, Mallows'un $\mathrm{Cp}$ kriteri, Akaike ve küçük örneklem düzeltmesi yapılmış Akaike bilgi kriteri ile Bayesyen (Schwarz) bilgi kriteri incelenmiştir (Tatoğlu, 2020a, 2020b).
} 
(2005)'nin çalışmaları izlenerek sermaye stoku verisi hesaplanmıştır². Beşerî sermayeyi temsilen ise, Fagerberg ve Verspangen (1999) ve Nickel vd. (2008) izlenerek ilköğretim okullaşma oranı kullanılmıştır. Göreli gelir ${ }^{3}$ ise, hem ülkeler arasındaki kişi başına düşen GSYİH yakınsamas1/1raksamasını ortaya koyan bir değişken, hem de teknolojik uyumlanmanın (technological imitation) bir vekil değişkeni olarak kullanılmaktadır (Guadagno, 2016). Bu nedenle bu çalışmada da göreli gelir, birlik içinde en yüksek kişi başına gelire sahip ülkeye göre hesaplanmıştır.

Bir ülkede yüksek enflasyonun varlığının o ülkedeki firmaların yatırım kararlarında caydırıcı etki yaptığı ve bunun özellikle reel sektör faaliyetlerini ve sermaye birikimini olumsuz yönde etkileyebileceğini gösteren çalışmalar mevcuttur (Bitros ve Panas, 2001; Rodrik, 2008; Kumar vd. 2012). Bu nedenle, enflasyon oranı da modele eklenmiştir. Bununla birlikte reel sektör faaliyetlerinde hem teknoloji yaratma kapasitesine katkı sağlaması (Schumpeter, 1911) hem de üretimin sürdürülebilirliğine olumlu etki yarattığı bilinen finansal alandaki gelişmeler de modelde dikkate alınmıştır. Finansal gelişmişlik düzeyinin etkisini ortaya koyabilmek için de temel olarak ekonomideki parasal büyüklük, dolaşımdaki para, likit borçlar, finans sektörünün sunduğu krediler dikkate alınmaktadır. Çalışmada ise veri seti bütünlüğünü en iyi sağlayan ve imalat sanayisine en fazla katkı sağlayacağı düşünülen bankaların özel sektöre sağladığı kredilerin GSYİH içindeki payı değişkeni modele dahil edilmiştir. Burada dikkat edilmesi gereken, bankaların sağladığı kredilerin tüm sektörlere sunulan kredileri kapsadığıdır. Bu nedenle elde edilen sonuçlar, bu kredilerin diğer ana sektörlere göreli olarak imalat sanayi katma değerini nasıl etkilediğini ortaya koymaktadır. Ülkenin ticari dışa açıklık oranının en önemli göstergesi olarak kabul edilen ticaret hacminin GSYİH içindeki payı da analize dahil edilmiştir. Çünkü, ticarete konu olan mallar dikkate alındığında $\mathrm{AB}$ üyesi ülkelerde hizmetler sektörü ihracatının GDP içindeki payının 2018 yılında \%25 ile sınırlı olduğu, imalat sanayi ihracatının ise oldukça önemli bir yere sahip olduğu bilinmektedir (World Development Indicators, 2019). Ayrıca, ticaret kapasitesinin artmasının hem doğrudan imalat sanayiyi hem de diğer sektörlerin imalat sanayi ile ileri ve geri bağlantıları nedeniyle dolaylı olarak imalat sanayi üretimini etkileyeceği ve bunun da yapısal değişimi tetikleyeceği düşünülmektedir (Singh, 1977; Chenery, 1982; Rodrik, 2008). 2008 küresel ekonomik krizinin sanayi sektöründe yaratmış olduğu etkiyi görmek amacıyla kriz yılı için kukla değişken de oluşturulmuştur.

Acemoğlu ve Robinson'un (2015) da vurguladığı gibi literatürde kurumların iktisadi faaliyetler üzerindeki etkilerini tartışmaya açan teorik ve ampirik çalışmalar giderek artmaktadır. $\mathrm{Bu}$ nedenle, yatırım olanaklarında özgürlük, mülkiyet hakları, ülkedeki vergi yükü, işletme kurma kolaylığ1 ve yönetimsel bütünlük/kapsayıcılık gibi alt endekslerden oluşan çeşitli iktisadi özgürlük endeksleri de kurumsal altyapıyı ve ülkelerin yönetişim kapasitesini ortaya koyan bir gösterge olarak modele eklenebilmektedir. Bu çalışmada da iktisadi özgürlük endeksinin bir alt değişkeni olan mülkiyet hakları endeks değerinin modele eklenmesi ile kurumsal kapasite ve kurumların niteliğinin imalat sanayi katma değeri üzerindeki etkisi anlaşılmaya çalış1lmıştır. Son olarak, önemli bir sosyoekonomik gösterge olan net göçmen sayısı da modele dahil edilmiştir. Bunun nedeni ise, özellikle $\mathrm{AB}$ 'de yaşanan beşinci genişlemenin etkisi ile iş gücünün, daha yüksek ücret sunan Batı Avrupa Birliği üye ülkelerine doğru bir göç dalgası yaratmış olduğunun düşünülmesidir (Pryymachenko vd., 2013). Bu göç dalgasının, sanayileşme üzerinde etkisi olması beklenmektedir.

\footnotetext{
${ }^{2} K_{t}=\sum_{i}^{M}(1-\beta)^{i} * I *(t-i)$. Burada, $\mathrm{K}_{\mathrm{t}}, \mathrm{I}, \beta$ ve $\mathrm{M}$ sırası ile t zamanındaki sermaye stokunu, $\mathrm{t}$ zamanındaki yatırımı, aşınma oranını ve ilk yatırımın ömrünü ifade etmektedir.

${ }^{3}$ Göreli Gelir: Belirli bir ülkeye göre ilgili ülkenin gelir düzeyini göstermektedir. İlgili ülkenin geliri/baz ülke geliri olarak hesaplanmaktadır. Çalışmada, 2018 yılında birlik içerisinde en yüksek gelire sahip ülke baz ülke olarak kabul edilmiştir.
} 
Tablo 1. Veri Seti Bilgileri

\begin{tabular}{ccc}
\hline Değişken Türü & Değişken Adı & Veri Tanımı \\
\hline Bağımlı Değişken & Y & İmalat Sanayi Katma Değeri (GSYİH içindeki \\
pay, \%)
\end{tabular}

Kaynak: Yazarlar tarafindan oluşturulmuştur.

Çalışmada kullanılan iktisadi özgürlük endeksi Miras (Heritage) resmî sitesinden; net göçmen sayısı Avrupa İstatistik Ofisi (Eurostat) resmi sitesinden; diğer tüm değişkenler ise Dünya Bankası (Worldbank) resmi sitesinden alınmıştır. Göç verilerinde, farklı yıllar için eksiklikler ile karşılaşılmıştır. Bu eksiklikler ise ülkelerin kendi istatistik kurumlarının veri tabanları kullanılarak ve metodoloji farkları gözetilerek tamamlanmıştır. Çalışmada, geometrik seri özelliği gösteren değişkenler (sermaye stoku, net göçmen sayısı ve kredi) doğal logaritmaları alınarak modele dahil edilmiştir. İlköğretim okullaşma oranı ve bankalar tarafından özel sektöre sağlanan krediler değişkenlerinin bir yıl gecikmeli değerleri kullanılmıştır.

\subsection{Yöntem ve Model}

Statik panel veri modellerinin aksine dinamik panel veri modelleri, bir iktisadi davranışın geçmiş deneyimlerin etkisinde olduğunu değişkenlerin gecikmeli değerlerini açıklayıcı faktörler olarak modele dahil edebilmektedir. Bağımlı değişkenin gecikmeli değerini içerecek şekilde bir dinamik panel veri modeli, denklem 1'deki gibi gösterilirken, burada bağımlı değişkenin gecikmeli değeri $\lambda_{i+} \varepsilon_{i t}$ ile ilişkili olmaktadır. Bu ilişkinin nedeni olarak kesitlere özgü heterojenliği ifade eden $\lambda_{i}$ 'nin her grubun her bir değişken için aynı olması gösterilebilir (Yıldırım ve Kostakoğlu, 2015). Bununla birlikte, bağımlı değişkenin gecikmeli değeri, gözlenemeyen etkilerle de korelasyona neden olmaktadır (Baltagi, 2005: 135-139).

$$
y_{i t}=\beta^{\prime} x_{i t}+\alpha y_{i, t-1}+\lambda_{i}+\varepsilon_{i t} \quad i=1, \ldots, N, \text { ve } t=1, \ldots, T
$$

Otoregresif modeller standart EKK ile tahmin edildiğinde ardışık hata terimleri ilişkili olacağından otokorelasyon nedeni ile etkin olmayan tahminciler elde edilmektedir. Otokorelasyon dikkate alınarak tahmin edilen EKK'da ise bağımlı değişkenin gecikmeli değerlerinin hata terimi ile ilişkili olması dışsallık varsayımını bozmakta, tahminciler sapmalı ve tutarsız olmaktadır (Grene, 2000). Rassal etkiler modelinde, bağımsız değişken ile birim etki arasındaki korelasyon temel problem olarak belirtilirken, sabit etkiler modelinde ise bağımsız değişkenler ile birim etkilerin korelasyonlu olması modelin temel varsayımlarını ihlal 
etmemektedir. Sabit etkiler varsayımıyla yapılan grup içi dönüşüm birim etkiyi yok edebilmekte, grup içi tahminci ile gölge değişkenli EKK tahmincisi aynı sonucu vermektedir. Ancak, Tatoğlu (2020b: 119), gölge değişkenli EKK tahmincisinin birim boyutu zaman boyutundan büyükken tutarsız olacağını gösteren Nickell sapmasına -bir başka adıyla dinamik panel sapması- dikkat çekerek, bu durumda tahmincilerin tutarsız olacağını vurgulamaktadır. Bu nedenle, Anderson ve Hsiao (1981), Arellano ve Bond (1991), Arellano ve Bover (1995) ve Blundell ve Bond (1998) farklı tahmin yöntemleri önermişlerdir. Andersen ve Hsiao (1981), dinamik panel veri modelinde birinci fark dönüşümü yaparak tahmin yapmaktadır ancak gecikmeli bağımlı değişken içsel olmakta yani modelin bağımsız değişkeni hata terimi ile ortogonel olmamaktadır. $\mathrm{Bu}$ da sapmalı tahminciler elde edilmesine sebep olmaktadır. Arellano ve Bond (1991) ise, gecikmeli değişkenlerden geçerli olanların tamamının araç değişken olarak kullanıldığı Genelleştirilmiş Momentler Tahmincisi (GMM) yöntemini önermektedir. Yöntemin ilk aşamasında birinci fark modeli dönüştürülmekte, ikinci adımda ise model genelleştirilmiş EKK yöntemi ile tahmin edilmektedir (Tatoğlu 2018b: 129). GMM yöntemi sabit etkiler ve içsellik sorununu çözmede önemli araçlar sunmakta ayrıca dinamik panel sapmasından kaçınmak için de etkin bir yöntem olarak kabul edilmektedir (Roodman, 2009b: 136). Bununla birlikte iki aşamalı tahmin yönteminin daha dirençli sonuçlar verdiği ifade edilmektedir (Arellano ve Bover, 1995; Blundell ve Bond, 1998).

Dinamik panel veri modelleri tahmin edilirken hangi yöntemin tercih edileceği üç unsur çerçevesinde değerlendirilmektedir. Bunlar, hata teriminin otokorelasyonlu olup olmadığı, bağımsız değişkenlerin tam dışsal olup olmadığı ve zaman ve birim boyutlarıdır (Tatoğlu, 2020b:155). Roodman da (2009a), Arellano ve Bond (1991) tahmincisinin $N>T$ olduğu durumlarda kullanılabileceğine işaret etmektedir. Bu durumda, yapılan sınamalar ışığında ve bu çalışma kapsamında $\mathrm{N}=25, \mathrm{~T}=23$ olduğundan Arellano ve Bond tahmincisinin kullanımının uygun olduğu görülmektedir. Çalışmada, sanayileşme sürecinin dinamik bir yapıya sahip olmasından ve yukarıda sıralana ekonometrik gerekçelerden dolayı dinamik panel veri analizi kapsamında, iki aşamalı sistem GMM yöntemi kullanılmaktadır. Kullanılacak olan sistem GMM modeline ait 2 numaralı denklem aşağıda gösterilmiştir.

$$
\begin{array}{r}
Y_{i, t}=\beta_{0}+\beta_{1} Y_{i, t-1}+\beta_{2} \text { Sermaye }_{i, t}+\beta_{3} \text { Eğitim }_{i, t-1}+\beta_{4} \text { Gelir }_{i, t}+\beta_{5} \text { Ticaret }_{i, t}+ \\
\beta_{6} \text { Kredi }_{i, t-1}+\beta_{7} \text { Kriz }_{t}+\beta_{8} \text { Enf }_{i, t}+\beta_{9} \text { Kurum }_{i, t}+\beta_{10} \text { Göç }_{i, t}+\varepsilon_{i, t}
\end{array}
$$

Yukarıda sunulan 2 numaralı denklemde, $Y_{i, t}$ sanayileşmeyi, $Y_{i, t-1}$ t-1 dönemindeki birikimli sanayileşme düzeyini, Sermaye yazarlar tarafından hesaplanan sermaye stokunu, Eğitim $_{t-1}$ beşeri sermayeyi, Gelir ${ }_{i, t}$ birlik içinde en yüksek kişi başına düşen gelire sahip ülkeye göreli olarak kişi başına düşen gelir düzeyini ve teknolojik uyumu, Ticaret $_{i, t}$ toplam ticaret hacminin GSYİH içindeki payı ile dışa açıklı̆̆ Kredi $_{i, t-1}$ t-1 döneminde bankalar tarafindan özel sektöre sağlanan toplam yerel kredilerin GSYIH içindeki payı ile finansal alandan sağlanan desteği, $\mathrm{Kriz}_{t}$ küresel ekonomik krizi, Enf $f_{i, t}$ yıllık enflasyon oranını, Kurum ${ }_{i, t}$ mülkiyet hakları endeksi ile ülkenin girişimin desteklenmesi ve korunması, demokrasi ve hukuk konularındaki kurumsal yapısını, $G$ öçi,t ülkeye gerçekleşen net göç düzeyini temsil etmektedir.

\section{ANALIZ SONUCLARI}

Avrupa Birliği'ne üye ülkelerde sanayileşmenin temel belirleyicileri AB-25 özelinde 1995-2018 yılları için analiz edilmiştir. Değişkenlere ait tanımlayıcı özet istatistikler Ek_1'de, korelasyon matrisi ise Ek_2'de sunulmuştur. Çalışma kapsamında öncelikle, statik model tahminleri yapılarak temel varsayımlar kontrol edilmiştir. Klasik EKK (En Küçük Kareler) modelinin geçerli olabilmesi gerekli homojenlik koşulunun sağlanabilmesi için birim etkilerin 
varlı̆ğı1 sorgulayan $F$ test sonucuna göre $(F(24,566)=81.56$, p=0.0000), birim ve zaman etkilerinin olmadığını söyleyen $\mathrm{H}_{0}$ hipotezi reddedilmektedir' ${ }^{4}$. Bu nedenle, klasik EKK'nın kullanılamayacağı, sabit ya da rassal etkiler modellerinin incelenmesi gerektiği görülmektedir. Sabit ve rassal modeller arasında seçim yapmaya olanak tanıyan Hausman spesifikasyon testi sonucuna göre $(\mathrm{Chi} 2=21.17, \mathrm{p}=0.0119)$, parametreler arasındaki farkın sistematik olmadığını söyleyen $\mathrm{H}_{\mathrm{o}}$ hipotezi kabul edilmiş, bu nedenle Tablo 1'de yalnızca rassal etkiler modeli sonuçlarına yer verilmiştir.

Tablo 2. Rassal Etkiler Modeli Sonuçları

\begin{tabular}{lcc}
\hline & Değişkenler & Katsayılar \\
\hline Sermaye & -0.2033 \\
\hline Eğitim & $-0.0130^{*}$ \\
\hline Gelir & $+7.9358^{* * *}$ \\
\hline Ticaret & $+0.470^{* * *}$ \\
\hline Kredi & $-1.5674^{* * *}$ \\
\hline Kriz & $-2.1665^{* * *}$ \\
\hline Enf & -0.0021 \\
\hline Kurum & -0.0045 \\
\hline Göç & -0.2044 \\
\hline Sabit & $+4.0484 * * *$ \\
\hline Gözlem Sayısı & 600 \\
\hline Rkare & 0.44 \\
\hline
\end{tabular}

Kaynak: Yazarlar tarafindan oluşturulmuştur.

*,**,*** strastyla \%10,\%5, \%1 anlamlilı düzeyini göstermektedir.

Rassal etkiler modelinde sonuçların güvenilirliğini test edebilmek için; otokorelasyon, değişen varyans ve yatay kesit bağımlılığı varsayımları kontrol edilmiştir. Değişen varyans probleminin kontrolü için Breusch ve Pagan LM test (chi2 (25) $=100.23$; Prob $>$ chi2 $=0.0000$ ), otokorelasyon kontrolü için Baltagi Wu'nun LBI testi (0.6816) ve Bhargava, Franzini ve Narandranathan'ın Durbin-Watson testi (0.5399) kullanılmıştır. Test sonuçları sabit etkiler modeli için hem değişen varyans hem otokorelasyonun varlığına işaret etmektedir. Ayrıca, yatay kesit bağımlılı̆̆ da birim boyutu zaman boyutundan büyük olan örneklemde $(\mathrm{N}>\mathrm{T})$ kullanılabilen Pesaran CD test ile sinanmış, buna göre (Test skoru: 9.2873, p=0.0000) $\mathrm{H}_{0}$ hipotezi reddedilerek serilerde yatay kesit bağımlılığının olduğu ortaya konmuştur. Tüm bu bilgilerden hareketle, bu çalışmada hem sanayileşme sürecinin dinamik yapısı hem de statik modelde yukarıda bahsedilen ekonometrik problemlerin varlığı nedeniyle otoregresif dinamik bir model kurgulanmıştır 5 .

Analiz çerçevesinde denklem 2'de sunulan model iki aşamalı sistem GMM modeli ile tahmin edilmiştir. Öncelikle dinamik panel veri modellerinde temel varsayımların testleri

\footnotetext{
${ }^{4}$ Bununla birlikte, çoklu doğrusal bağlantının varlığını sınayan VİF testine ve kriterine göre, $2.88<5$ olduğundan çoklu doğrusal bağlantı olmadığına, Jarqua Bera Testine göre hata terimlerinin normal dağıldığına $(\mathrm{p}=0.0010)$ karar verilmiştir (Tatoğlu, 2020a). Wooldridge otokorelasyon testi $(\mathrm{F}(1,24)=84.705, \mathrm{p}>\mathrm{F}=0.0000)$ ve Breusch-Pagan / Cook-Weisberg değişen varyans testi $(\operatorname{chi} 2(1)=92.44, \mathrm{p}>$ chi2 $=0.0000)$ sonuçları da otokorelasyonun ve değişen varyans probleminin olduğuna işaret etmektedir.

${ }^{5}$ Arellano-Bond ve Arellano-Bover tahmincilerinin hangi durumlarda kullanılabileceği ile ilgili ayrıntılı bilgi için bkz. (Roodman, 2009a).
} 
yapılmıştır. Modelde yer alan içsel değişkenlerin yerine kullanılan araç değişkenlerin hata terimleri ile korelasyonsuz (dışsal) olup olmadıkları, Durbin Score ve Wu-Hausman testleri ile sınanmıştır (Tatoğlu, 2020b). Test sonuçlarına göre (Durbin (score) chi2(1)= 0.234764; $\mathrm{p}=0.6280)$, Wu-Hausman $(\mathrm{F}(1,538)=0.22974 ; \mathrm{p}=0.6319)$, değişkenlerin dışsal olduğunu söyleyen temel hipotez reddedilememiştir, yani değişkenler dışsaldır. Yapılan analizde Wald testi bağımsız değişkenlerin, bağımlı değişkeni açıklamada anlamlı olduğunu göstermektedir. Bununla birlikte, GMM tahmininde kullanılan araç değişkenlerin geçerli olup olmadığı, bir başka ifade ile aşırı kısıtlamaların geçerli olup olmadığını sınamak için Sargan testi önerilmektedir (Tatoğlu, 2020b). Tablo 2'de sunulan Sargan testi sonucu da seçilen araç değişkenlerin geçerli olduğunu ortaya koymaktadır. Ayrıca Arellano-Bond AR(1) testine göre de birinci dereceden otokorelasyonun olduğu ancak Arellano-Bond AR(2) testine göre ikinci dereceden otokorelasyonun olmadığı görülmektedir. Bu tablo, GMM tahminlerinin tutarlı ve bu nedenle de katsayıların yorumlanabilir olduğunu göstermektedir ${ }^{6}$. Buna ek olarak, Sanayileşme $t-1$ değişkeninin istatistiksel olarak anlamlı olması, GMM yönteminin kullanımının uygunluğuna işaret etmektedir.

Tablo 2, 1995-2018 döneminde AB-25 için sanayileşmenin belirleyicilerini sunmaktadır. Buna göre, ilgili dönemde sermaye stoku, beşerî sermaye stoku, göreli gelir, ticaret hacmi, enflasyon, bankalar tarafından özel sektöre sağlanan krediler, kurumsal altyapı ve 2008 krizi sanayileşmeye etki eden temel faktörler olarak tespit edilmiştir. Göçün sanayileşme üzerine etkisi tespit edilmemiştir.

Tablo 3. Arellano ve Bond İki Aşamalı Dinamik Panel Veri Analizi Sonuçları

\begin{tabular}{|c|c|}
\hline Değişkenler & Katsayılar \\
\hline Sanayileşmet-1 & $(+) 0.7388 * * *$ \\
\hline Sermaye & $(+) 0.2151 * *$ \\
\hline Ĕgitimt-1 & $(+) 0.0202 * *$ \\
\hline Gelir & (+) $0.3584 *$ \\
\hline Ticaret & $(+) 0.0352 * * *$ \\
\hline Kredit-1 $_{\text {- }}$ & (-) $0.2598 *$ \\
\hline Kriz & (-) $1.5042 * * *$ \\
\hline Enf & (+) $0.0028 * * *$ \\
\hline Kurum & $(+) 0.01807 *$ \\
\hline Göç & (-) 0.4583 \\
\hline Sabit & $(+) 4.5813 * * *$ \\
\hline Arellano-Bond AR(1) & (-) $1.71 \quad(p=0.088)$ \\
\hline Arellano-Bond AR(2) & $(-) 0.95 \quad(p=0.341)$ \\
\hline Wald & $2501.63 \quad(p=0.0000)$ \\
\hline Sargan & $22.44 \quad(p=0.675)$ \\
\hline Araç değişken sayısı & 17 \\
\hline
\end{tabular}

\footnotetext{
${ }^{6}$ Dinamik panel veri modellerinde, birinci dereceden otokorelasyon sıklıkla karşıllaşılan bir durum olup, ikinci dereceden otokorelasyon varlığının olmaması önemlidir (Baum ve Schaffer, 2013).
} 
Sermaye stokundaki bir artış, beklendiği gibi sanayileşmeyi pozitif etkilemektedir. İmalat sanayi üretimine pozitif ve anlamlı etki etmesi beklenen beşerî sermaye stoku değişkeni olarak ilköğretim okullaşma oranı, beklentilerle uyumlu olarak anlamlı ve pozitiftir. Duyarlılık analizleri kapsamında bu değişken yerine ortaöğretim ve yüksek öğretim okullaşma oranlarıyla da tahminler yapılmıştır. Bu tahminlerin sonuçları eğitim seviyesi arttıkça, yani ülkelerin beşerî sermaye stokunun niteliği arttıkça imalat sanayi katma değeri üzerindeki etkinin negatife döndüğ̈nü göstermiştir. Bu durum, analiz yıllarında emeğin üretimdeki payının azalmış olmasının bir sonucu olarak yorumlanabileceği gibi, bireylerin eğitim düzeyleri arttıkça imalat sanayi dışındaki sektörlere yönelme eğilimlerinin de arttığını biçiminde de yorumlanabilir.

Göreli gelir değişkeni, hem makroekonomik genel görünümün en önemli göstergesi olan genel gelir düzeyine ilişkin yakınsama ve ıraksama trendini ortaya koyması hem de bir baz ülkeye göre teknolojik uyumlanmayı da göstermesi bakımından önemlidir. Analiz sonucunda yakınsama katsayısı 0,35 olarak elde edilmiştir. Bu durum AB-25 ülkelerinde gelir açısından ve teknolojik uyum kapasitesi açısından en ileri ülkeye yakınsama eğiliminde olduğunu göstermektedir.

Dışa açıklık göstergeleri olarak hem toplam ticaretin GSYİH'deki payı hem de dış ticaret hacmi değiş̧enleri değerlendirilmiştir. Analiz sonucunda, bu iki değişkenin de etkisi her zaman anlamlı ve pozitiftir. Ancak literatürde dışa açıklığın en yaygın göstergesi, toplam ticaretin GSYIHH'deki payı olarak kabul edildiğinden nihai modelde bu değişken kullanılmıştır. Bu doğrultuda ülkedeki ticaret kapasitenin artmasının imalat sanayi katma değerini arttırıcı etki yaptığı söylenebilmektedir. Analiz sonucuna göre ülkedeki ticaret kapasitenin artmasının, imalat sanayi katma değerini arttırıcı etki yaptığı söylenebilmektedir.

Makroekonomik istikrarın göstergesi kabul edilen enflasyonun ise sanayileşme üzerindeki etkisi de istatistiksel olarak anlamlı ve pozitiftir. Dolayısı ile elde edilen sonuç, yüksek enflasyonun firmaların yatırım kararları üzerinde caydırıcı bir etki yapacağı beklentisi ile uyumlu değildir. Bankaların özel sektöre sağladığı kredilerin sanayileşme üzerine etkisi ise negatiftir. Sanayileşmeye negatif etki eden bir diğer değişken ise, 2008 krizidir. Reel sektörü uzun yıllar etkisi altına alan küresel ekonomik krizin de beklentilerle uyumlu olarak sanayileşmeyi negatif etkilediği görülmektedir ve bu etki oldukça yüksektir.

Sosyoekonomik göstergelerin sanayileşme üzerindeki etkisine ilişkin sonuçlar da oldukça dikkat çekicidir. Hukuk kurallarının, adaletli yönetimin ve demokratik yaşamın bir göstergesi kabul edilen iktisadi özgürlük endeksinin bir bileşeni olan mülkiyet hakları endeksi dikkate alındığında, kurumsal altyapı kapasitesi ya da iyi yönetişim göstergesi olarak kabul edilebilecek olan endeks değerinin etkisi istatistiksel olarak anlamlı ve pozitiftir. Buna göre, ülkede iktisadi mülkiyet haklarının korunmasına yönelik iyileştirici bir müdahale yani endeks değerindeki bir artış, sanayileşmeye pozitif etki etmektedir. Bu doğrultuda, AB-25 ülkelerinde mülkiyet haklarının korunması, girişim ortamında özgürlüğün sağlanması vb. alanlarda iyileştirmelerin yapılmasının, imalat sanayi katma değerine pozitif etki edeceği söylenebilir. Diğer bir sosyoekonomik gösterge olan göçün sanayileşmeye etkisi ise istatistiksel olarak anlamsız bulunmuştur. $\mathrm{Bu}$ durum, AB'nin genişleme politikalarının özellikle Batı Avrupa ülkelerine niteliksiz göç akımı yarattığı/yaratacağını düşünen kuşkucu görüşün (Trichet, 2004; Lammers, 2004) beklentilerini desteklememektedir.

\section{GENEL DEĞERLENDİRME}

$\mathrm{AB}$ üyesi ülkeler genel olarak incelendiğinde, özellikle beşinci genişlemenin yaşandığı 2004 yılına kadar birlik içerisinde gelişmiş, bir diğer ifade ile sermaye yoğun üretim yapan ülkelerin bulunduğu görülmektedir. Yaşanan beşinci genişleme ile gelişmekte olan ülkeler birliğe eklenmiş olsa da genel olarak birlik içerisindeki sanayi yapısı, orta ve üzeri teknolojiye 
dayanan, sermaye yoğun bir görünüm sunmaktadır. Bu kapsamda özellikle İngiltere ve Almanya başta olmak üzere $\mathrm{AB}$ ülkelerinde sanayi sektörü, büyümenin ve kalkınmanın önemli bir gücü olarak kabul edilmekte ve bu ülkeler ekonomik ve sosyal yapıda önemli değişimlere öncü olarak dünyada sanayileşmenin gelişim sürecine yön vermektedir. 2010 yılını takiben Almanya öncülüğünde ilan edilen ve üretimde otomasyon, robotik üretim gibi gelişmeleri içeren yeni sanayileşme süreci, önümüzdeki yıllarda $\mathrm{AB}$ ülkelerinin de yeni bir sanayileşme sürecine gireceğini göstermektedir. $\mathrm{Bu}$ nedenle $\mathrm{AB}$ ülkelerinde sanayi sektörü hem politika yapıcılar hem de uygulayıcılar tarafından iyi analiz edilmeli ve sektör çok boyutlu ve kapsayıcı bir bakış açısı ile ele alınmalıdır. Sanayileşme sürecine olumlu katkılar sağlayacak iktisadi ve sosyal koşulların yeniden inşası da sürecin ilk basamağı olmalıdır.

Yeni bir sanayi yol haritasının oluşturulmasında en önemli nokta ekonomik ve sosyal değişim ve dönüşümleri dikkate alan modelleri temel almaktır. Bu nedenle sanayileşmeyi çeşitli açılardan ele alan çalışmalara ihtiyaç giderek artmaktadır. Bu noktadan hareketle çalışmada, literatürdeki çalışmalar ve AB-25'in özellikleri dikkate alınarak sanayileşmeyi etkileyen faktörler sistem GMM yöntemi kullanılarak araştırılmıştır. Bu kapsamda, 1995-2018 dönemi için AB-25'te sanayileşmenin temel belirleyicileri; sermaye ve beşerî sermaye stoku, dişa açıklık, göreli gelir, enflasyon, bankalar tarafindan özel sektöre sağlanan krediler ve 2008 küresel ekonomik krizi gibi temel ekonomik göstergeler ile kurumsal altyapıyı temsilen mülkiyet hakları endeksi gibi sosyoekonomik genel görünümle de ilişkili olan göstergelerdir.

Elde edilen sonuçların genel olarak beklentiler ile uyumlu olduğu görülmektedir. Sermaye stoku ve beşerî sermaye stokunun sanayileşmeyi pozitif etkilemesi teoriyle uyumlu, beklenen bir sonuçtur. Dışa açıklık olarak ifade edilen ticaret hacminin GSYİH içindeki payı arttıkça, imalat sanayi üretimi pozitif etkilenmektedir. Bu durum, özellikle AB'ye üye ülkelerin birlik içi ticaret hacimlerinin de yüksek olduğu dikkate alındığında, üye ülkelerin birbirleri ile olan ticaret ilişkilerine yönelik düzenlemelere ayrıca önem verilmesi gerektiğini işaret etmektedir. Diğer yandan, AB'ye üye ülkelerde ticaretin genişlemesiyle imalat sanayi katma değerinin artış göstermesi, küresel ekonomideki diğer partnerlerle ticari ilişkilerin düzenlenmesinin ve $A B$ 'ye üye ülkelerin ticari ortaklıklarının geleceğinin stratejik bir şekilde planlanmasının gerektiğini de göstermektedir. Enflasyon ve bankalar tarafindan finans sektörüne sağlanan kredilerin sanayileşme üzerine etkileri ise, beklentiler ile uyumlu değildir. Enflasyon, sanayileşmeye pozitif etki yaparken, bankalar tarafindan özel sektöre sağlanan kredilerin sanayileşme üzerine negatif etkisi olduğu görülmüştür.

Son olarak, AB'ye üye ülkelerde kurumsal altyapının ve daha genel olarak iyi yönetişimi temsilen modele eklenen mülkiyet hakları endeksi yani kurum değişkeni ile imalat sanayi arasında pozitif ve anlamlı bir ilişkinin ortaya konması bu ülkeler için çok önemli bir bulgudur. Özellikle son yıllarda genişleme politikaları, finansal kriz, göç ve Brexit gibi önemli gündem maddelerinden sonra bu ülkelerin doğru adımları atması yalnızca siyasi açıdan değil, analizden de anlaşılacağı gibi ekonomik ve sosyal açılardan da son derece önemlidir. Bu nedenle AB üyesi ülkelerin, sanayileşme yol haritalarında iktisadi özgürlük endeksinin tüm alt bileşenlerine yönelik kapsayıcı reformlar ve düzenlemeler yapmalarının sanayi üretimini de olumlu etkileyeceği düşünülmektedir. Ayrıca sosyoekonomik bir gösterge olarak göçün sanayi üretimi üzerine anlamlı bir etkisi bulunamamıştır.

Özetle, elde edilen bulgular, sanayileşmenin tarihsel belirleyicilerinde ülkelerdeki makroekonomik göstergeler kadar sosyal ve kurumsal gelişmelerin de önemli olduğunu ortaya koymaktadır. Bu çerçevede, beşerî sermaye stokunun niteliğini arttıracak ve sanayi üretimine katkısını arttıracak politikalar son derece önemlidir. Özellikle Sanayi 4.0'1n getirdiği yeni iş alanları ve bu işlerin gerektirdiği becerilere yönelik eğitim reformlarının uygulaması önerilebilir. İlaveten, uzun süreli makroekonomik istikrarın sağlanması, etkili ve stratejik ticaret politikalarının uygulanması, girişim özgürlügüne, mülkiyet haklarına, kurumların şeffaf ve 
sorunsuz çalışmasına önem verilmesi dolayısı ile demokratik yönetimin sürdürülebilirliğinin sağlanması AB'ye üye ülkelerin sanayileşme süreçlerine önemli katkılar sağlayacaktır. Üç temel sektörden biri olan imalat sanayi katma değerinin temel belirleyicilerini tespit etmeyi amaçlayan bu çalışma bulgularından yola çıkarak gelecek çalışmalarda, AB ekonomisinin alt sektörlerindeki üretimin yapısal farklılıklarının da ayrıştırılacağı kapsamlı ampirik çalışmaların yapılması planlanmaktadır.

\section{Araştırma ve Yayın Etiği Beyanı}

Bu çalışma bilimsel araştırma ve yayın etiği kurallarına uygun olarak hazırlanmıştır.

\section{Yazarların Makaleye Katkı Oranları}

Çalışma 5 bölümden oluşmaktadır. İlk yazarın katkısı \%50, ikinci yazarın katkısı \%50’dir.

\section{Çıkar Beyanı}

Yazarlar açısından ya da üçüncü taraflar açısından çalışmadan kaynaklı çıkar çatışması bulunmamaktadır. 


\section{KAYNAKÇA}

Acemoğlu, D. ve Robinson, A. J. (2015). Ulusların Düşüşü: Güç, Zenginlik ve Yoksulluğun Kökenleri. (Çev. F.R. Velioğlu). İstanbul: Doğan Kitap.

Ambroziak, A. A. (2015). Europeanization processes from the mesoeconomic perspective: industries and policies. In W. P, Stanek \& K. Wach (Eds.), Europeanization of industrial policy: towards re-industrialisation. Kraków: Uniwersytet Ekonomiczny w Krakowie.

Anderson, T. W. \& Hsiao, C. (1981). Estimation of dynamic models with error components. Journal of the American Statistical Association, 76(375): 598-606.

Arellano, M. \& Bover. O. (1995). Another look at the instrumental variable estimation of error-components models. Journal of Econometrics, 68(1), 29-51.

Arellano, M. \& Bond, S. (1991). Some tests of specification for panel data: Monte Carlo evidence and an application to employment equations. The review of economic studies, 58(2), 277-297.

Baum, F. C. \& Schaffer E. M. (2013). A general approach to testing for autocorrelation. Boston: Boston College.

Bitros, George C. \& Panas E. E. (2001). Is there an inflation-productivity trade-off? Some evidence from the manufacturing sector in Greece. Applied Economics, 33(15), 1961-1969.

Blundell, R. \& Bond, S. (1998). Initial conditions and moment restrictions in dynamic panel data models. Journal of econometrics, 87(1), 115-143.

Castelo-Branco, I., Cruz-Jesus F. \& Oliveira, T. (2019). Assessing Industry 4,0 readiness in manufacturing: Evidence for the European Union. Computers in Industry, 107, 22-32.

Chenery, H. (1982). Industrialization and growth: The experience of large countries. (The World Bank., No. SWP539).

Cornwall, J. (1977). Modern Capitalism, Its Growth and Transformation, New York: St.

Council of the European Communities. (1992). Treaty on European Union, Luxembourg: Office for Official Publications of the European Communities.

Czirfusz, M., Barta G. \& Kukely, G. (2008). Re-industrialisation in the World and in Hungary. European Spatial Research and Policy, 15(2), 5-27.

Dağlı, İ., \& Ezanoğlu, Z. (2021). Ar-Ge, Patent ve İleri Teknoloji İhracatının Ekonomik Büyümeye Etkileri: Oecd Ülkeleri İçin Dinamik Panel Veri Analizi. Itobiad: Journal of The Human \& Social Science Researches, 10(1).

Eurofound (European Foundation for the Improvement of Living and Working Conditions). (2019). The future of manufacturing in Europe. Luxembourg: European Union.

Fagerberg, J. \& Verspagen, B. (1999). Modern Capitalism'in the 1970s and 1980s, Growth, employment and inflation, London: Palgrave Macmillan.

Gilchrist, A. (2016). Industry 4.0: The industrial internet of things. Berkeley: Apress.

Guadagno, F. (2016). The determinants of industrialisation in developing countries, 1960-2005. United Nations University-Maastricht Economic and Social Research Institute on Innovation and Technology (MERIT No. 2016031).

Greene, W. H. (2000). Econometric analysis. International edition, New Jersey: Prentice Hall.

Hadri, K. \& Kurozumi, E. (2012). A simple panel stationarity test in the presence of serial correlation and a common factor. Economics Letters, 115(1), 31-34.

Heymann, E. ve Vetter, S. (2013). Europe's re-industrialisation the gulf between aspiration and reality. Frankfurt am Main: Deutsche Bank AG, DB Research.

Jaegers, T., Lipp-Lingua, C. \& Amil D. (2013). High-technology and medium-high technology industries main drivers of EU-27's industrial growth. Statistics in Focus, https://ec.europa.eu/eurostat/web/products-statistics-in-focus/-/ks-sf13-001, Erişim Tarihi: 30.05.2021.

Kaldor, N. (1966). Causes of the slow rate of economic growth of the United Kingdom: an inaugural lecture. London: Cambridge UP.

Karadag, M., Önder, Ö. A. \& Deliktaş, E. (2005). Growth of factor productivity in the Turkish manufacturing industry at provincial level. Regional Studies. 39(2), 213-223. 
Kozal, E. Ö. ve Barbaros, F. R. (2019). Türkiye'de Sanayi 4,0 Dönüşümünün Olanakları ve Kısıtları Üzerine Bir Değerlendirme. Ege Stratejik Araştırmalar Dergisi, 10(2), 19-42.

Kumar, S., Webber, D. J. \& Perry, G. (2012). Real wages, inflation and labour productivity in Australia. Applied Economics, 44(23), 2945-2954.

Kutu, A. A. \& Ngalawa, H. (2016). Dynamics of industrial production in BRICS countries, International Journal of Economics and Finance Studies. 8(1), 1-25.

Lammers, K. (2004). How will the enlargement affect the old members of the European Union?. Intereconomics, 39(3), 132-141.

Landes, S. D. (1969). The unbound Prometheus: technological change and industrial development in Western Europe from 1750 to the present, Cambridge: Cambridge University Press.

Marconi, N., Fróes de Borja Reis, C. \& Cristina de Araújo, E. (2016). Manufacturing and economic development: The actuality of Kaldor's first and second laws. Structural Change and Economic Dynamics, 37, 75-89.

Mazhar, U. \& Rehman, F. (2019). Manufacturing as a Growth Escalator in Low and Middle Income Countries. Journal of Economics and Finance, 44, 1-20.

McCausland, W. D. \& Theodossiou, I. (2012). Is manufacturing still the engine of growth?. Journal of Post Keynesian Economics, 35(1), 79-92.

Naudé, W., Szirmai, A. \& Lavopa, A. (2013). Industrialization lessons from BRICS: A comparative analysis. (IZA Discussion Paper Series. No. 7543).

Nickell, S., Redding S. \& Swaffield, J. (2008). The uneven pace of deindustrialisation in the OECD. World Economy, 31(9), 1154-1184.

O'Brien, K. P. (2001). Metanarratives in global histories of material progress. The International History Review, 23(2), 345-367.

Pesaran, H. M. (2007). A simple panel unit root test in the presence of cross-section dependence. Journal of Applied Econometrics, 22(2), 265-312.

Pryymachenko, Y., Fregert K. \& Andersson, F. (2013). The effect of emigration on unemployment: Evidence from the Central and Eastern European EU member states. Economics Bulletin, 33(4), 2692-2697.

Robinson, S., Syrquin, M. \& World Bank. (1986). Industrialization and growth: a comparative study, New York: Published for the World Bank, Oxford University Press.

Roodman, D. (2009a). How to do xtabond2: an introduction to difference and system gmm in stata. The Stata Journal, 9(1), 86-136.

Roodman, D. (2009b). A Note on the Theme of Too Many Instruments, Oxford Bulletin of Economics and Statistics, $71,135-158$.

Rodrik, D. (2007). Industrial Development: Some Stylized Facts and Policy Directions. Industrial Development for the 21st Century. U.N. Department of Economic and Social Affairs: Division for Sustainable Development.

Rodrik, D. (2008). The Real Exchange Rate and Economic Growth. Brookings Papers on Economic Activity, 2, 365412.

Rodrik, D. (2016). Premature deindustrialization, Journal of economic growth. 21(1), 1-33.

Schumpeter, A. J. (1911). The theory of economic development, Cambridge: Harvard University Press.

Singh, A. (1977). UK industry and the world economy: A case of de-industrialization? Cambridge Journal of Economics, 1(2), 183-214.

Szirmai, A. (2012). Industrialisation as an engine of growth in developing countries, 1950- 2005. Structural Change and Economic Dynamics, 23(4), 406-420.

Szirmai, A. \& Verspagen, B. (2015). Manufacturing and economic growth in developing countries, 19502005. Structural Change and Economic Dynamics, 34, 46-59.

Tatoğlu, F. Y. (2020a). Panel Veri Ekonometrisi: Stata Uygulamalı, 1. Bask1, İstanbul: Beta Yayınc1lı.

Tatoğlu, Y. F. (2020b). Illeri Panel Veri Ekonometrisi: Stata Uygulamalı, 4. Bask1, İstanbul: Beta Yayınc1lı.

Temple, J. \& Voth, H-J. (1998). Human capital, equipment investment, and industrialization. European Economic Review, 42(7), 1343-1362. 
Optimum Journal of Economics and Management Sciences, Vo1. 9, No. 1- https://dergipark.org.tr/tr/pub/optimum Erdölek Kozal and Gürel Günal - Determinants of Industrialization in Member States of the European Union: Dynamic Panel Data Analysis

Thirlwall, P. A. (2003). The nature of economic growth: an alternative framework for understanding the performance of nations. Northampton: Edward Elgar Publishing.

Timmer, Marcel P. \& Szirmai, A. (2000). Productivity growth in Asian manufacturing: the structural bonus hypothesis examined. Structural Change and Economic Dynamics, 11(4), 371-392.

Trichet, J-C. (2004). EU Enlargement: Challenges and Opportunities. Conference on Europe's Frontiers: EU Enlargement - Its Implications and Consequences.

Westkämper, E. (2014). Towards the re-industrialization of Europe: a concept for manufacturing for 2030. Berlin: Springer.

World Bank. (2019). World Development Indicators. https://databank.worldbank.org/source/world-developmentindicators, Erişim Tarihi: 20.03.2020 


\section{EKLER}

Ek_1: Değişkenlere ait Özet Betimleyici İstatistikler

\begin{tabular}{cccccc}
$\begin{array}{c}\text { Değişken } \\
\text { Türü }\end{array}$ & $\begin{array}{c}\text { Gözlem } \\
\text { Sayısı }\end{array}$ & Ortalama & $\begin{array}{c}\text { Standart } \\
\text { Sapma }\end{array}$ & $\begin{array}{c}\text { Minimum } \\
\text { Değer }\end{array}$ & $\begin{array}{c}\text { Maksimum } \\
\text { Değer }\end{array}$ \\
\hline Y & 600 & 16.06335 & 4.223231 & 7.236187 & 34.5663 \\
Kredi & 600 & 4.414774 & .6968702 & 1.468703 & 5.523442 \\
Ĕgitim & 600 & 106.8777 & 16.99388 & 74.15001 & 164.8277 \\
Sermaye & 600 & 16.06335 & 4.223231 & 7.236187 & 34.5663 \\
Enf & 600 & 5.910883 & 44.19145 & -4.478103 & 1058.374 \\
Kurum & 600 & 69.43633 & 18.8157 & 30 & 95 \\
Göç & 600 & 4.625796 & .7275674 & 1.544068 & 6.188605 \\
Gelir & 600 & 2.040899 & 2.876499 & .0402644 & 11.05123 \\
Ticaret & 600 & 95.3375 & 40.26779 & 22.15427 & 226.0414
\end{tabular}

Ek_2: Korelasyon Matrisi

\begin{tabular}{|c|c|c|c|c|c|c|c|c|c|}
\hline & Sanayileşme & Kredi & Eğitim & Sermaye & Enf & Kurum & Göç & Gelir & Ticaret \\
\hline Sanayileşme & 1.000 & & & & & & & & \\
\hline Kredi & -0.3623 & 1.000 & & & & & & & \\
\hline Ĕgitim & -0.202 & 0.4539 & 1.000 & & & & & & \\
\hline Sermaye & -0.1736 & 0.7181 & 0.3969 & 1.000 & & & & & \\
\hline Enf & 0.0804 & -0.1579 & -0.4256 & -0.4617 & 1.000 & & & & \\
\hline Kurum & 0.0264 & 0.5668 & 0.5528 & 0.5195 & -0.3731 & 1.000 & & & \\
\hline Göç & -0.1504 & 0.6349 & 0.3537 & 0.8776 & -0.4165 & 0.4629 & 1.000 & & \\
\hline Gelir & -0.1087 & 0.6861 & 0.6286 & 0.7059 & -0.4706 & 0.7331 & 0.6376 & 1.000 & \\
\hline Ticaret & 0.3319 & -0.0712 & 0.1875 & -0.4067 & -0.0421 & 0.0137 & -0.3688 & -0.0795 & 1.000 \\
\hline
\end{tabular}




\section{Extended Summary}

\section{Determinants of Industrialization in Member States of the European Union: Dynamic Panel Data Analysis}

Industrialization has been discussed that has been important since the Industrial Revolution in the context of the contributions of countries to economic growth and development processes. Industrialization, which was accepted the same with economic growth and then economic development from the 18th century to the second half of the 20th century, remained in the background with the rise of the accumulation processes based on financial capital since the second half of the 20th century. However, with the 2008 global financial crisis, almost all countries' economies were negatively affected, and this crisis led to new quests in the economic paradigm. Then, with the impact of new developments in technology and the changing structure of production patterns all over the world, industrialization discussions under industry 4.0 and the concept of re-industrialization have regained speed in recent years, especially in Europe. In summary, in the 21st century, the world economy has been facing a new wave of industrialization and major transformations in industrialization dynamics. All these developments cause countries/policy makers to search for new policies suitable for the period with a multidimensional perspective.

Discussions about industrialization can be analyzed on two axes. The first axis was dealt empirically, primarily by Kaldor (1967) and Cornwall (1977) and consisted of studies analyzing whether industrialization is the engine of growth. The second axis, while testing the engine of growth hypothesis, also reveals the main historical determinants of industrialization. The most noticeable in the discussions about whether the manufacturing industry is the engine of growth and the determinants of industrialization is the analysis that focuses on the distinction between developed and developing countries. Few studies focus on specific country groups or international organizations, in other words economic or political country blocks. In the world where the economic and social outlook is differentiating, it is becoming more and more important that empirical studies aiming to design industrialization policies focus on economic, political or geographical regional clusters. It is very important to focus on the EU, which includes the leading countries in the industrialization wave, especially since the limits of accumulation based on financial capital and the global financial crisis in 2008 were questioned. It is known that the re-industrialization debates in the EU have been brought to the agenda with the developments in recent years. This situation led to the search for new regional policies in EU member countries. All these developments have revealed the need for an industrial strategy that will restructure the manufacturing industry production in the EU member countries, which can be considered as one of the most important manufacturing production regions in the world. In order to contribute to this roadmap, the dynamics affecting industrialization must first be determined in these countries. Therefore, this study aims to determine the factors that determine industrialization in EU-25 countries between 1995-2018. It is anticipated that the discovery of the basic variables that determine the manufacturing industry production in the EU member countries, where Industry 4.0 and the re-industrialization debates are gaining momentum, will contribute significantly to the capacity of policy making for economic growth and development.

In this study, because the industrialization process has a dynamic structure, two-stage system GMM model is used within the scope of dynamic panel data analysis. In the Model, 25 EU member states were taken into consideration, and Malta, Cyprus and Luxembourg were not included in the sampling due to gaps in the data set. However, within years of analysis, the UK was added to the model as it became an EU member state. In the analysis made for 1995-2018, as the dependent variable the share of manufacturing value added in GDP is used a proxy of industrialization. In addition to this, the determinants of industrialization for the EU-25 are capital and human capital stock, relative income, trade openness, inflation rate, property right 
index, domestic credits provided by banks to private sector, and 2008 global economic crisis. The variables were determined by following the important studies in the literature.

It is seen that an increase in the capital stock and human capital have made a significant and positive contribution to industrialization in line with the expectations. As a result of the increase in trade volume, the industry sector is positively affected, and openness affects industrialization through the trade channel. Relative income, which is one of the main indicators of macroeconomic conditions and technological imitation, has a significant effect on industrialization. This indicate that there is a convergence of income in the EU-25 countries. Inflation, which is accepted as an indicator of macroeconomic stability, is statistically significant for industrialization, but the sign of the effect is not in line with the expectation. The credit variable, which represented by domestic credits provided by banks to private sector, is also statistically significant and has negative impact on manufacturing production. It is seen that the global economic crisis in 2008 also negatively affected industrialization as expected. Within the scope of the analysis, it was observed that credits provided by the financial sector were statistically insignificant.

One of the remarkable points within the scope of the results is one of the socio-economic indicators has an important effect on industrialization. Positive developments in the property right index, which is accepted as an indicator of legal rules, justice administration and democratic life, in short, good governance, will accelerate industrialization. The effect of migration, another socio-economic indicator on industrialization is statistically insignificant. This can be accepted as one of the most important findings of this study because results shows that there is no negative impact of migration on industrialization which is opposite with the skeptics' idea.

In summary, the findings reveal that social and institutional developments are as important as the macroeconomic indicators in countries in the historical determinants of industrialization. These finding can lead the policy makers of the EU countries to create a road map for re-industrialization. In this framework, countries need to focus on attracting qualified workforce and implement education reforms to the unskilled workforce for the new jobs brought by industry 4.0 and the skills required to do these jobs. In addition to that, ensuring long-term macroeconomic stability, implementing effective and strategic trade policies, and guaranteeing the sustainability of good governance will make significant contributions to the EU's industrialization processes. 
Optimum Journal of Economics and Management Sciences, Vo1. 9, No. 1- https://dergipark.org.tr/tr/pub/optimum Erdölek Kozal and Gürel Günal - Determinants of Industrialization in Member States of the European Union: Dynamic Panel Data Analysis 